\title{
Synthesis, Characteristics, and Material Properties Dataset of Bi:DyIG-Oxide Garnet-Type Nanocomposites
}

\author{
M. Nur-E-Alam, Mikhail Vasiliev, and Kamal Alameh \\ Electron Science Research Institute, Edith Cowan University, 270 Joondalup Drive, Joondalup, WA 6027, Australia \\ Correspondence should be addressed to M. Nur-E-Alam; m.nur-e-alam@ecu.edu.au
}

Received 10 April 2015; Accepted 14 May 2015

Academic Editor: Enrico Bergamaschi

Copyright ( 2015 M. Nur-E-Alam et al. This is an open access article distributed under the Creative Commons Attribution License, which permits unrestricted use, distribution, and reproduction in any medium, provided the original work is properly cited.

\begin{abstract}
The fabrication, annealing crystallization processes, and material properties of $(\mathrm{Bi}, \mathrm{Dy})_{3}\left(\mathrm{Fe}, \mathrm{Ga}_{5} \mathrm{O}_{12}: \mathrm{Bi}_{2} \mathrm{O}_{3}\right.$ nanocomposites are investigated and summarized. The stoichiometry of these nanocomposites is optimized for magnetooptic applications using the approach of stoichiometry adjustment (implemented by means of varying RF power densities applied to the sputtering targets used to prepare the nanocomposite thin films). The crystallization processes for all developed batches of as-deposited films are carried out by annealing runs at different temperatures and process durations. This paper describes the methodologies used to optimize the compositions (by calculating the volumetric fractions of excess bismuth oxide to be mixed with the garnet-stoichiometry species during cosputtering processes) and to obtain the optical and magnetooptical properties data and presents the materials properties summary of garnet-bismuth oxide thin film composites as well.
\end{abstract}

\section{Introduction}

The development of new photonic materials (including Bisubstituted iron garnet compounds) is required to keep up with the technological demands and challenges of today's world, especially because most innovative technologies require more advanced, high-performance, stable, functional, and specialized low-cost materials. Bismuth-substituted iron garnets are used as magnetooptic (MO) functional materials for various emerging and existing applications in integrated optics and photonics. However, these are still limited to using bulk garnet layers. Most of the high-speed optical communication systems work in the near-infrared spectral region, where $\mathrm{MO}$ garnet materials can perform particularly well. Visible-range devices such as magnetooptic imagers and magnetic field sensing devices often employ Bi-substituted iron garnets due to their extraordinary MO properties. These materials are also very promising for the development of magnetic photonic crystals, magnetoplasmonic crystals, and the production of nanostructured magnetic field landscapes for cold atom manipulation, $\mathrm{MO}$ waveguides, and ultrafast optoelectronic devices, such as light intensity switches and modulators for optical communications [1-8]. These substances have been studied since the 1960s, and multiple groups worldwide have been working on customizing the various garnet materials properties by synthesizing garnet films and nanocrystals of different nominal compositions $[1,2,9-19]$. The authors of this paper have previously reported on the synthesis and characterization of Bi-substituted iron garnets of composition type $(\mathrm{Bi}, \mathrm{Dy})_{3}(\mathrm{Fe}, \mathrm{Ga})_{5} \mathrm{O}_{12}$ and also on their improved $\mathrm{MO}$ quality factors. The latter has been achieved by fabricating garnet- $\mathrm{Bi}_{2} \mathrm{O}_{3}$ nanocomposites having a combination of remarkable physical properties, which showed great promise for applications in next-generation integrated optics, nanophotonics, and also in reconfigurable photonics [2]. These new garnet-type materials developed by synthesizing garnet-oxide nanocomposites are relatively easy to integrate into the existing integrated optics manufacturing processes and can assist in achieving cost-efficiency by providing the functional materials, which are technologically compatible with the presently used material combinations. The latter is due to (i) the very good compatibility of sputtering processes with many other microfabrication technologies and (ii) the relatively moderate process temperature needed for the synthesis of these garnet-oxide materials. These new garnet materials will have influence on numerous industries in the future, because most of the innovative technologies requiring these advanced materials will be easy to implement 
TABLE 1: RF magnetron cosputtering process parameters and conditions used to fabricate various magnetooptic garnet-oxide thin films of type $\left(\mathrm{Bi}_{2} \mathrm{Dy}_{1} \mathrm{Fe}_{4} \mathrm{Ga}_{1} \mathrm{O}_{12}: \mathrm{Bi}_{2} \mathrm{O}_{3}\right)$.

\begin{tabular}{|c|c|}
\hline $\begin{array}{l}\text { Process parameters used for thin film } \\
\text { garnets preparation }\end{array}$ & Values \& comments \\
\hline Sputtering target compositions & $\begin{array}{l}\mathrm{Bi}_{2} \mathrm{Dy}_{1} \mathrm{Fe}_{5-x} \mathrm{Ga}_{x} \mathrm{O}_{12} \text { (where } x=1 \text { and } 0.7 \text { ) and } \mathrm{Bi}_{2} \mathrm{O}_{3} \text { (the materials' purity was } \\
99.99 \% \text { for all targets) }\end{array}$ \\
\hline Dimensions of targets & $3^{\prime \prime}$ dia. $\times 0.125^{\prime \prime}$ thick, bonded to $0.125^{\prime \prime} \mathrm{Cu}$ backing plates \\
\hline Sputter gas and pressure & $\operatorname{Argon}($ Ar. $), P($ total $)=1-2$ mTorr \\
\hline Base pressure inside vacuum chamber & $P$ (base) $<1-4 E-6$ Torr \\
\hline RF power densities for garnets & $3.3-7 \mathrm{~W} / \mathrm{cm}^{2}(150-320 \mathrm{~W})$ \\
\hline RF power densities for $\mathrm{Bi}_{2} \mathrm{O}_{3}$ & $0.44-3.96 \mathrm{~W} / \mathrm{cm}^{2}(20-180 \mathrm{~W})$ \\
\hline Substrate temperature & $250-400^{\circ} \mathrm{C}$ \\
\hline Partial deposition rates for garnets & $3.5-9.0 \mathrm{~nm} / \mathrm{min}$ \\
\hline Partial deposition rates for $\mathrm{Bi}_{2} \mathrm{O}_{3}$ & $1.2-5.0 \mathrm{~nm} / \mathrm{min}$ \\
\hline Annealing temperature & $490-680^{\circ} \mathrm{C}$ \\
\hline Annealing process duration & $\begin{array}{l}(<1)-180 \text { minutes, with the ramp-up/ramp-down rates of } 3-5^{\circ} \mathrm{C} / \mathrm{min} \text { when using a } \\
\text { conventional box-furnace-type temperature-controlled air-atmosphere } \\
\text { oven-annealing system (Sentro Tech, Inc., USA) }\end{array}$ \\
\hline Properties characterized & Optical, magnetic, and MO properties of all nanocomposite films \\
\hline Characterization techniques used & $\begin{array}{l}\text { Spectrophotometry, custom thin film optimization software, Thorlabs PAX } \\
\text { visible-range polarimetry system in conjunction with a custom-made calibrated } \\
\text { electromagnet, and transmission-mode polarization microscopy (Leitz Orthoplan). }\end{array}$ \\
\hline
\end{tabular}

and less costly. The dataset generated in this paper is based on our materials research and development activities conducted during the past couple of years in the area of garnet thin films synthesis.

In particular, this paper reports on the summary of materials' composition optimization, process parameterrelated data including the data describing the sputtering and annealing processes, characteristic material-related properties, and also the annealing effects on their optical and MO performance. The characteristic data obtained for several optimized garnet-oxide composites represent the outcomes of our experimental efforts and provide a set of information resources for the production of thin film garnets of high optical quality and impressive MO performance that will likely be required for many advanced integrated optics and photonics applications.

\section{Methodologies}

2.1. Sample Preparation. Bismuth-substituted (Dy,Ga) doped iron garnet-bismuth oxide composite films (multiple deposition batches) were prepared on glass (Corning 1737) and monocrystalline gadolinium gallium garnet (GGG) substrates using an RF magnetron cosputtering technique in low-pressure (1-2 mTorr) pure-argon plasma with no extra oxygen input. The process parameters and conditions used to deposit (nonreactively) the garnet-oxide composites from two separate targets (oxide-mix-based $(\mathrm{BiDy})_{3}(\mathrm{FeGa})_{5} \mathrm{O}_{12}$ and $\mathrm{Bi}_{2} \mathrm{O}_{3}$ ) are summarized in Table 1 . Before depositing any composite garnet layers, the presputtering processes for both garnet and bismuth oxide targets were performed at least for 10-30 minutes to bring them into stable sputtering conditions and also to measure the partial deposition rates of materials.
The deposition rates were monitored and measured during all presputtering processes by using a well-calibrated quartz crystal microbalance sensor.

The deposition rates of both component materials (garnet and $\mathrm{Bi}_{2} \mathrm{O}_{3}$ ) were controlled by varying the RF power densities applied by RF power generators through automatic impedance-matching networks to the sputtering targets. This composition-control methodology enabled obtaining the optimized sample compositions by using the material design considerations, as well as trial and error. The estimated amounts of the volumetric fraction of excess bismuth oxide (since some $\mathrm{Bi}_{2} \mathrm{O}_{3}$ was already present within garnet targets) were calculated by using the partial deposition rates from both targets observed during the presputtering processes. The basic formula that was used to calculate the vol.\% fraction of excess bismuth oxide in our composite-type layers (in as-deposited samples, before any phase changes took place during annealing) is shown in the following [20]:

$$
\begin{aligned}
& \text { Vol. } \% \text { of excess of } \mathrm{Bi}_{2} \mathrm{O}_{3} \\
& =\frac{\text { Deposition rate of } \mathrm{Bi}_{2} \mathrm{O}_{3}}{\text { Total deposition rate (garnet } \left.+\mathrm{Bi}_{2} \mathrm{O}_{3}\right)} .
\end{aligned}
$$

The samples composition adjustments trialed (the amounts of excess bismuth oxide added into the composite layers) as well as their best-obtained performance (specific Faraday rotation and MO figures of merit measured across the visible spectral range) from all batches of composites are summarized in Tables 2 and 3 . The growth rate of composite garnet-oxide layers and the layer thicknesses were monitored during the deposition processes using a quartz crystal microbalance sensor and a custom-made in situ real-time laser reflectometry system (designed and made at Edith Cowan University) 


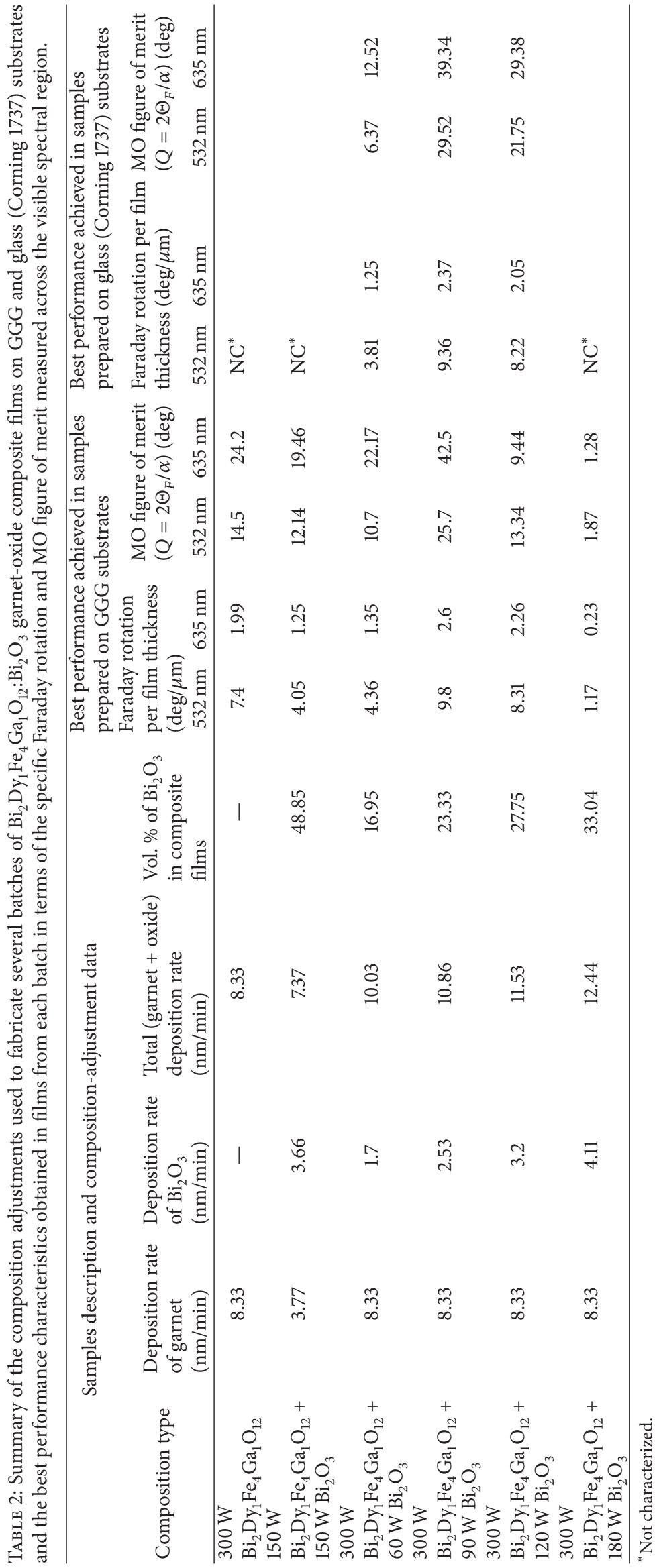




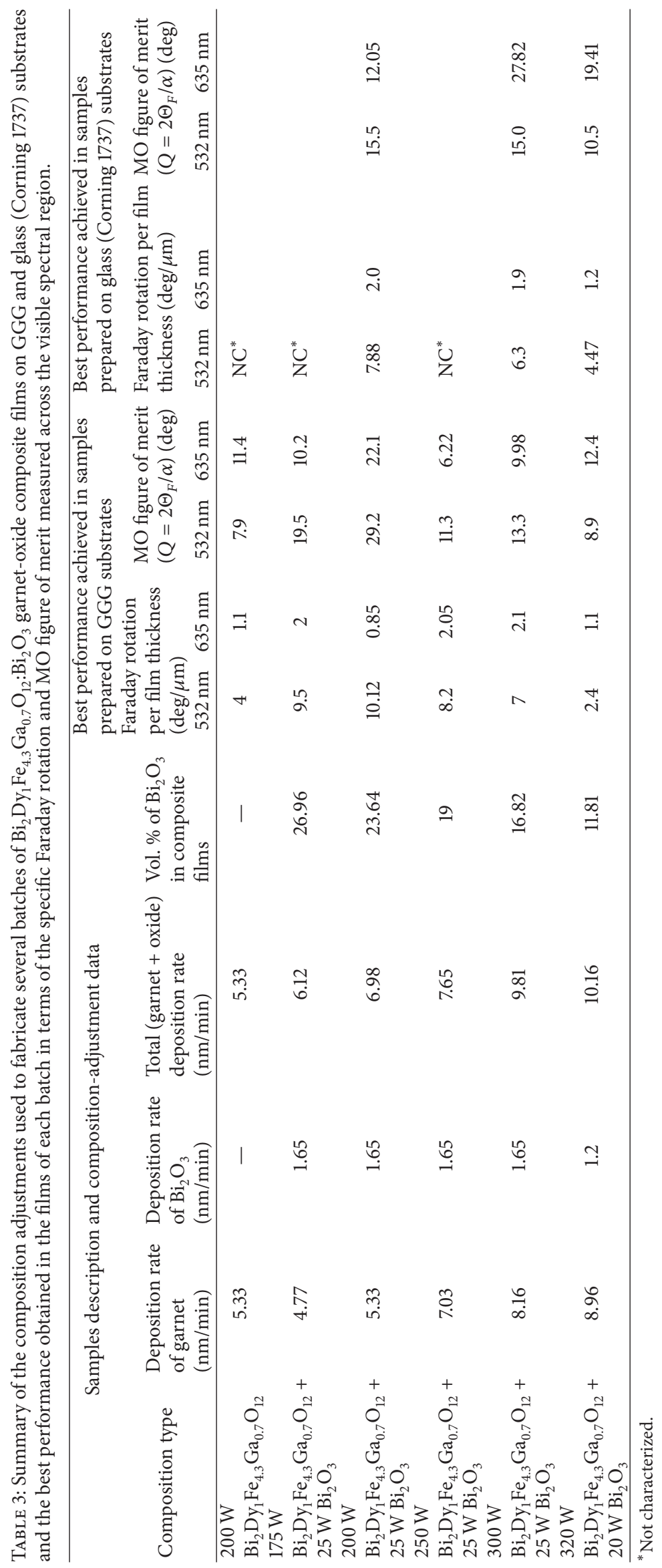


integrated with the sputtering system (KVS-T 4065, Korea Vacuum Technology Ltd.). The actual films' growth rate always slightly varied from that observed and measured during the presputtering process. This might have been due to the slow temperature increases at the sputtering target surfaces expected to occur during the relatively long sputtering deposition processes. The actual layer thicknesses were reconfirmed by fitting of their optical transmission spectra obtained using a spectrophotometer to their modeled transmission spectra using an in-house built specialized software package (based on NET Framework's Managed C++) which allows us to perform the modeling and measured-data comparison of the transmission, reflection, and absorption spectra of thin film materials (single-layer or multilayer type) as well as design optimized magnetic photonic crystals (MPC) structures [20]. All batches of composite (asdeposited) layers containing up to nearly 50 vol. $\%$ of excess $\mathrm{Bi}_{2} \mathrm{O}_{3}$ sputtered onto GGG (111) and glass (Corning 1737) (typical layer thickness was $500-1100 \mathrm{~nm}$ ) were annealed using a conventional oven-annealing system. Samples from each batch were subjected to several trials of annealing processes using different temperatures and time duration to find the optimized annealing regimes for the particular batch of samples. The optimization of annealing regimes was extremely important for the garnet films to achieve the desired physical properties (optical and magnetic). It was also found that the optimized annealing regimes for the composite garnet-oxide layers were significantly dependent on the films' composition. We were able to optimize the annealing regimes (in terms of the process temperature and time duration) for each batch of newly synthesized materials. Furthermore, it was found that the "thermal processing windows" most suitable for crystallizing the garnet-oxide composites, as was confirmed by the excellent combinations of the films' properties demonstrated in most batches. The estimated absolute accuracy of temperature measurement was about $\pm 10^{\circ} \mathrm{C}$ which did not affect significantly the repeatability of the properties seen in the annealed garnet-oxide films of different compositions, even in films having very large volumetric contents of excess bismuth oxide.
2.2. Sample Characterizations and Materials' Performance Data Evaluation. The optical and MO properties of garnet materials are essentially important for the development of various multifunctional device applications in integrated optics devices and advanced photonics. The optical transmission spectra of MO garnet-oxide composite films were measured using an UV/Visible (Beckman Coulter DU640B) spectrophotometer and we determined the optical absorption spectra (a very important spectrally dependent dataset for all applications of thin film materials) using softwareassisted rigorous point-by-point fitting of the measured transmission spectra. The real thicknesses of all garnet layers were also determined for each sample by using the iterative fitting of their measured transmission spectra to the theory-predicted spectra whilst accounting for the accurately measured spectral data for the dispersion of the refractive index and absorption coefficients, as reported by our group [21]. Significantly lower than typical literaturereported optical absorption coefficients were achieved in our RF-sputtered garnets and nanocomposites. A comparative study of optimized absorption coefficient spectra obtained after running various annealing processes for a range of garnet-oxide composites synthesized on two different substrate types (GGG and Corning 1737 glass) was presented in [2]. The MO quality (MO figure of merit) is defined as doubled ratio of the specific Faraday rotation to the optical absorption coefficient, and this quantity needs to be characterized spectrally by performing measurements at each particular wavelength. Specific Faraday rotations (and also magnetic hysteresis loop measurements) were performed for all of our annealed samples using a Thorlabs Inc. PAX optical polarimeter system in conjunction with a custommade well-calibrated electromagnet system and two specific plane-polarized laser light sources (emitting at $532 \mathrm{~nm}$ and $635 \mathrm{~nm}$ ). The following calculations were performed to obtain data for the specific Faraday rotation as well as for the MO figure merit of our annealed composite films:

$$
\text { Specific Faraday rotation } \Theta_{F}=\frac{\text { Rotation angle (one way) at remnant magnetization }}{\text { Film thickness }(d)}(\mathrm{deg} / \mu \mathrm{m}) \text {, }
$$

$$
\text { MO figure of merit } Q=2 \times \frac{\theta_{F}}{\alpha}(\mathrm{deg}) \text {, }
$$

where $\alpha$ is optical absorption coefficient.

The MO figures of merit for all (annealed) samples were calculated taking into account the measurement errors in the films' thickness (within estimated $\pm 5 \%$ accuracy) as well as in Faraday rotation angles. The estimated error bars for the MO figure of merit were calculated by considering the achievable maximum and also minimum error-affected Qfactors for each sample, using the upper and lower error limits relevant to the measurements of the films' thickness as well as Faraday rotation angles. The record-high MO figures of merit (plotted with the error bars shown) obtained in our composite films were reported in [2]. Annealing crystallization studies (using either oven-annealing or rapid thermal annealing processes) of thin films are an important part of modern research in the field of garnet materials. The transformation of amorphous-phase garnets into the micro- or nanocrystalline phase requires careful process development and operator attention and can lead to obtaining 
TABLE 4: Dataset obtained from the annealing study of $\mathrm{Bi}_{2} \mathrm{Dy}_{1} \mathrm{Fe}_{4.3} \mathrm{Ga}_{0.7} \mathrm{O}_{12}: \mathrm{Bi}_{2} \mathrm{O}_{3}$ garnet-oxide composite films (having 17 vol.\% of excess bismuth oxide) prepared on GGG substrates and the corresponding optical/MO properties measured at $532 \mathrm{~nm}$ and $635 \mathrm{~nm}$.

\begin{tabular}{|c|c|c|c|c|c|c|c|}
\hline \multirow[b]{2}{*}{$\begin{array}{l}\text { Annealing } \\
\text { temperature }\left({ }^{\circ} \mathrm{C}\right)\end{array}$} & \multirow[b]{2}{*}{$\begin{array}{l}\text { Annealing process } \\
\text { duration } t \text { (min) }\end{array}$} & \multicolumn{3}{|c|}{ Properties measured at $532 \mathrm{~nm}$} & \multicolumn{3}{|c|}{ Properties measured at $635 \mathrm{~nm}$} \\
\hline & & $\begin{array}{c}\text { Specific Faraday } \\
\text { rotation } \\
(\mathrm{deg} / \mu \mathrm{m})\end{array}$ & $\begin{array}{l}\text { Absorption } \\
\text { coefficients } \\
\left(\mathrm{cm}^{-1}\right)\end{array}$ & $\begin{array}{l}\text { MO figure } \\
\text { of merit } \\
(\text { deg })\end{array}$ & $\begin{array}{c}\text { Specific Faraday } \\
\text { rotation } \\
(\mathrm{deg} / \mu \mathrm{m})\end{array}$ & $\begin{array}{l}\text { Absorption } \\
\text { coefficients } \\
\left(\mathrm{cm}^{-1}\right)\end{array}$ & $\begin{array}{c}\text { MO figure } \\
\text { of merit } \\
\text { (deg) }\end{array}$ \\
\hline \multirow{8}{*}{550} & $<1$ & $\mathrm{NA}^{*}$ & NC & NC & $\mathrm{NC}$ & NC & NC \\
\hline & 15 & $\mathrm{NA}^{*}$ & NC & NC & NC & NC & NC \\
\hline & 22 & 0.63 & 9040 & 1.39 & 0.033 & 1458 & 0.50 \\
\hline & 27 & 7.2 & 5997 & 24 & 2.062 & 1130 & 36.49 \\
\hline & 30 & 4.23 & 8331 & 10.15 & 0.986 & 1473 & 13.38 \\
\hline & 45 & 5.65 & 6736 & 16.77 & 1.733 & 1484 & 23.35 \\
\hline & 60 & 6.71 & 8563 & 15.67 & 1.828 & 2769 & 13.20 \\
\hline & 90 & 6.35 & 7732 & 16.42 & 1.63 & 2153 & 15.14 \\
\hline \multirow{11}{*}{560} & 4 & $\mathrm{NA}^{*}$ & NC & $\mathrm{NC}$ & $\mathrm{NC}$ & NC & NC \\
\hline & 7 & 3.60 & 8201 & 8.78 & NC & NC & $\mathrm{NC}$ \\
\hline & 12 & 7.04 & 6950 & 20.25 & 2.019 & 1700 & 23.75 \\
\hline & 15 & 6.9 & 6332 & 21.8 & 2.138 & 1382 & 30.94 \\
\hline & 22 & 7.07 & 6145 & 23.01 & 2.062 & 1365 & 30.21 \\
\hline & 26 & 6.51 & 8201 & 15.87 & 1.8 & 2572 & 13.99 \\
\hline & 30 & 6.38 & 7720 & 16.52 & 1.81 & 2162 & 16.74 \\
\hline & 45 & 7.31 & 6477 & 22.57 & 1.938 & 1449 & 26.75 \\
\hline & 52 & 7.07 & 8125 & 17.40 & 2.004 & 3337 & 12.01 \\
\hline & 60 & 6.45 & 9361 & 13.78 & 1.828 & 2347 & 15.57 \\
\hline & 90 & 6.97 & 7232 & 19.27 & $\mathrm{NC}$ & NC & $\mathrm{NC}$ \\
\hline \multirow{7}{*}{570} & 1 & 2.9 & 8857 & 6.53 & 0.381 & 1867 & 4.08 \\
\hline & 2 & 7.03 & 5950 & 23.63 & 1.88 & 1097 & 34.27 \\
\hline & 4 & 7.02 & 6332 & 22.17 & 2.128 & 1021 & 41.60 \\
\hline & 6 & 7.1 & 9315 & 15.25 & 2.119 & 2922 & 14.50 \\
\hline & 8 & 7.56 & 10353 & 14.60 & 2.168 & 3519 & 12.32 \\
\hline & 9 & 6.98 & 8956 & 15.58 & 1.95 & 3213 & 12.13 \\
\hline & 12 & 7.5 & 11428 & 13.12 & 2.076 & 4131 & 10.05 \\
\hline
\end{tabular}

${ }^{*}$ Not annealed or Faraday rotation was below detection limit. NC: not characterized.

samples which are either "underannealed" (showing small or even absent Faraday rotation) or "overannealed" (showing surface damage or material decomposition even with Faraday rotation). One batch of composite-type films of stoichiometry described by approximately 17 vol.\% of added extra bismuth oxide was chosen to study the annealing process-dependent evolution of the obtained film properties. This study was conducted by performing the annealing runs for this batch of composite films at three different crystallization temperatures $\left(550^{\circ} \mathrm{C}, 560^{\circ} \mathrm{C}\right.$, and $\left.570^{\circ} \mathrm{C}\right)$ using a range of annealing process durations (up to 120 minutes). All annealed samples grown on GGG and glass substrates were characterized comprehensively and their recorded performance is summarized in Tables 4 and 5. (The crystal-structure properties of our garnet-oxide composites were characterized using $\mathrm{X}$ ray diffractometry, and the magnetic domain patterns were observed in a range of materials using a transmission-mode polarization microscope. This data was published in other high-impact journals $[2,22]$.)
The evaluation of optical and magnetooptical properties can only be partially helpful to understand the crystallization kinetics relevant to these garnet-type thin film materials if the extent of crystallization is quantified (in a simplified way) as the ratio of the specific Faraday rotation measured in films after running any given annealing process, to the maximum specific Faraday rotation at the same wavelength achieved in any given material/substrate system after running the process at the same annealing temperature with the "best-known" parameters. All specific Faraday rotation data obtained from the samples deposited onto GGG substrates were measured in the remnant magnetization states, in order to exclude the paramagnetic effects of $0.5 \mathrm{~mm}$ thick GGG substrates, which led to measuring slightly increased Faraday rotation angles when placed in the electromagnet's saturation field of up to $2.5 \mathrm{kOe}$. For samples deposited onto Corning 1737 glass substrates, Faraday rotation data was taken at the saturation magnetization, even though all films maintained about $90 \%$ of Faraday rotation after being 
TABLE 5: Dataset obtained from the annealing study of $\mathrm{Bi}_{2} \mathrm{Dy}_{1} \mathrm{Fe}_{4.3} \mathrm{Ga}_{0.7} \mathrm{O}_{12}: \mathrm{Bi}_{2} \mathrm{O}_{3}$ garnet-oxide composite films (having 17 vol.\% of excess bismuth oxide) prepared on glass (Corning 1737) substrates and the corresponding optical/MO properties measured at $532 \mathrm{~nm}$ and $635 \mathrm{~nm}$.

\begin{tabular}{|c|c|c|c|c|c|c|c|}
\hline \multirow[b]{2}{*}{$\begin{array}{l}\text { Annealing } \\
\text { temperature }\left({ }^{\circ} \mathrm{C}\right)\end{array}$} & \multirow[b]{2}{*}{$\begin{array}{l}\text { Annealing process } \\
\text { duration } t \text { (min) }\end{array}$} & \multicolumn{3}{|c|}{ Properties measured at $532 \mathrm{~nm}$} & \multicolumn{3}{|c|}{ Properties measured at $635 \mathrm{~nm}$} \\
\hline & & $\begin{array}{c}\text { Specific Faraday } \\
\text { rotation } \\
(\mathrm{deg} / \mu \mathrm{m})\end{array}$ & $\begin{array}{c}\text { Absorption } \\
\text { coefficients } \\
\left(\mathrm{cm}^{-1}\right)\end{array}$ & $\begin{array}{l}\text { MO figure } \\
\text { of merit } \\
(\text { deg })\end{array}$ & $\begin{array}{c}\text { Specific Faraday } \\
\text { rotation } \\
(\mathrm{deg} / \mu \mathrm{m})\end{array}$ & $\begin{array}{c}\text { Absorption } \\
\text { coefficients } \\
\left(\mathrm{cm}^{-1}\right)\end{array}$ & $\begin{array}{c}\text { MO figure } \\
\text { of merit } \\
\text { (deg) }\end{array}$ \\
\hline \multirow{9}{*}{550} & $<1$ & $\mathrm{NA}^{*}$ & NC & NC & NC & NC & NC \\
\hline & 13 & $\mathrm{NA}^{*}$ & NC & NC & NC & NC & NC \\
\hline & 15 & 5.85 & 7564 & 15.46 & NC & NC & $\mathrm{NC}$ \\
\hline & 22 & 6.42 & 7221 & 17.78 & 2.024 & 1765 & 24.08 \\
\hline & 27 & 6.52 & 6671 & 19.54 & 2.41 & 1588 & 28.90 \\
\hline & 30 & 6.85 & 7072 & 19.37 & 2.35 & 1830 & 24.46 \\
\hline & 45 & 7.04 & 7495 & 18.78 & 2.395 & 2091 & 21.82 \\
\hline & 60 & 6.82 & 7495 & 18.19 & 2.343 & 1867 & 23.90 \\
\hline & 90 & 6.47 & 7228 & 17.90 & 2.31 & 1828 & 24.07 \\
\hline \multirow{10}{*}{560} & 4 & $\mathrm{NA}^{*}$ & NC & $\mathrm{NC}$ & NC & NC & NC \\
\hline & 7 & 6.28 & 8209 & 15.30 & NC & NC & NC \\
\hline & 12 & 6.54 & 7942 & 16.46 & 2.34 & 2026 & 23.09 \\
\hline & 15 & 6.74 & 8163 & 16.51 & 2.071 & 2082 & 19.89 \\
\hline & 22 & 6.57 & 7911 & 16.60 & 2.195 & 1857 & 23.64 \\
\hline & 26 & 6.74 & 7682 & 17.55 & 2.08 & 1943 & 21.41 \\
\hline & 30 & 7.2 & 6568 & 21.93 & 2.247 & 1941 & 23.15 \\
\hline & 45 & 6.76 & 7858 & 17.20 & 2.73 & 2103 & 25.96 \\
\hline & 52 & 6.67 & 7949 & 16.78 & 2.185 & 2151 & 20.32 \\
\hline & 60 & 7.1 & 6027 & 23.56 & 2.219 & 1821 & 24.37 \\
\hline \multirow{5}{*}{570} & 1 & 6.54 & 7873 & 16.61 & 2.07 & 2145 & 19.30 \\
\hline & 2 & 6.21 & 8167 & 15.20 & 2.257 & 2119 & 21.30 \\
\hline & 4 & 6.65 & 8068 & 16.48 & 2.23 & 2214 & 20.15 \\
\hline & 8 & 7 & 6881 & 20.35 & 2.267 & 1903 & 23.83 \\
\hline & 12 & 6.96 & 8064 & 17.26 & 2.295 & 2532 & 18.13 \\
\hline
\end{tabular}

${ }^{*}$ Not annealed or Faraday rotation was below detection limit. NC: not characterized.

removed from the electromagnet. The data obtained may not be sufficient to derive accurately the activation energy of crystallization for Bi-substituted iron garnets and garnettype nanocomposites; however these data reveal the general character and thermal dynamics of the annealing-induced isothermal-crystallization processes in these materials. A significant amount of characterization work was performed during this study, and the authors believe that it can provide a good source of data for further research efforts on the development of new garnet materials.

\section{Discussion}

Several batches of garnet-oxide composite-type thin films deposited onto both GGG and glass substrates were characterized and evaluated comprehensively. The results obtained describe a very promising class of garnet thin films of composition type $(\mathrm{BiDy})_{3}(\mathrm{FeGa})_{5} \mathrm{O}_{12}$.

Good crystallinity properties, surface quality, and attractive magnetic and MO performance characteristics were observed in most sample batches. The data (presented in
Tables 1-5) describe the methodology, parameters, and conditions relevant to the synthesis of performance-optimized garnet-oxide composite-type thin film materials and the ways of obtaining materials with specific properties. Figure 1 shows a glimpse into the obtained superior microstructural, magnetic, and magnetooptical properties in optimally annealed composite-type garnet films; (a) shows the $\mathrm{XRD}$ datasets of garnet-oxide layers of composition type $(\mathrm{BiDy})_{3}(\mathrm{FeGa})_{5} \mathrm{O}_{12}: \mathrm{Bi}_{2} \mathrm{O}_{3}$ prepared on Corning 1737 glass substrates. The strong peaks for (221), (220), (321), (400), (420), (422), (521), (444), (640), (642), (800), and (842) reflections planes originated at the $2 \theta\left({ }^{\circ}\right)$ values $17.25,19.95$, $26.55,28.35,31.8,34.95,39.25,50.35,52.55,54.65,58.75$, and 68.45 , respectively, confirmed their good crystalline quality and also the presence of garnet phase with body-centered cubic lattice type. The diffraction peak found at $44.5^{\circ}$ has revealed the XRD signature of $\mathrm{Fe}_{3} \mathrm{O}_{4}$ according to a search of JCPDS catalogue (JCPDS powder diffraction file number 28-0491) [23] which confirmed the hypothesis having larger visible-range optical absorption of sputtered garnet films [2]. The lattice parameter of crystallized $\mathrm{Bi}_{2} \mathrm{Dy}_{1} \mathrm{Fe}_{4} \mathrm{Ga}_{1} \mathrm{O}_{12}: \mathrm{Bi}_{2} \mathrm{O}_{3}$ 


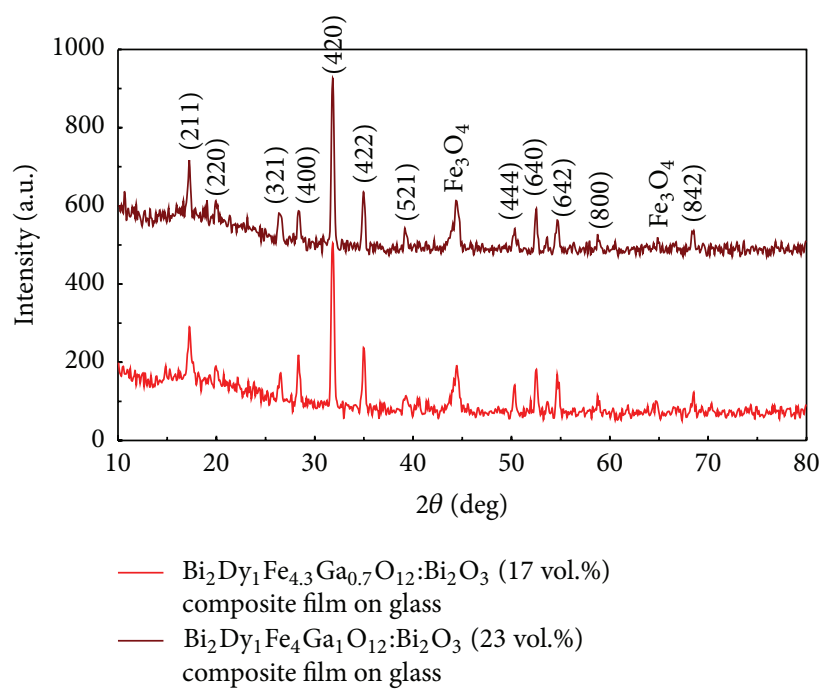

(a)

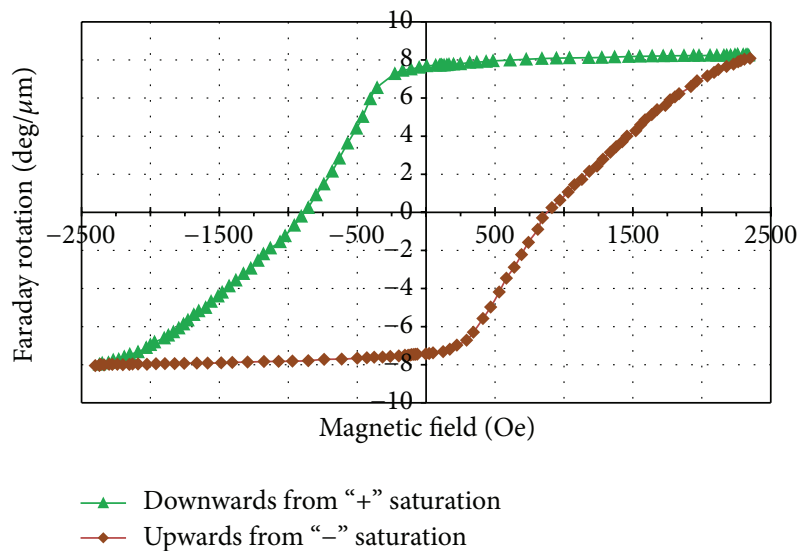

(b)

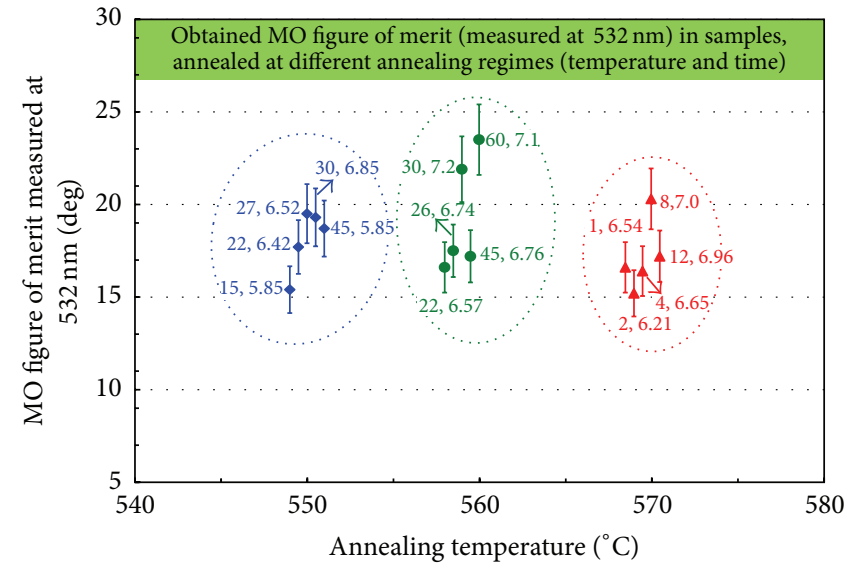

(c)

FIGURE 1: (a) XRD datasets of garnet-oxide layers of composition type $(\mathrm{BiDy})_{3}(\mathrm{FeGa})_{5} \mathrm{O}_{12}: \mathrm{Bi}_{2} \mathrm{O}_{3}$ deposited onto Corning 1737 glass substrates, (b) hysteresis loop of specific Faraday rotation measured in $\mathrm{Bi}_{2} \mathrm{Dy}_{1} \mathrm{Fe}_{4.3} \mathrm{Ga}_{0.7} \mathrm{O}_{12}: \mathrm{Bi}_{2} \mathrm{O}_{3}$ composite-type film (having estimated $24 \mathrm{vol} . \%$ of excess $\mathrm{Bi}_{2} \mathrm{O}_{3}$ ) grown on a Corning 1737 glass substrate, and (c) the evolution of measured MO figure of merit obtained in $\mathrm{Bi}_{2} \mathrm{Dy}_{1} \mathrm{Fe}_{4.3} \mathrm{Ga}_{0.7} \mathrm{O}_{12}: \mathrm{Bi}_{2} \mathrm{O}_{3}(17 \pm 2$ vol.\%) films prepared on glass substrates.

(23 vol.\%) grown on GGG (111) substrate was calculated using the formula derived from the combination of Bragg's equation and d-spacing expression and the calculated (averaged) lattice constant was found about $12.579 \AA[22,24]$. The predicted stoichiometry for the garnet-oxide composite layer was $\mathrm{Bi}_{2.4} \mathrm{Dy}_{0.6} \mathrm{Fe}_{4} \mathrm{Ga}_{1} \mathrm{O}_{12}$, and this was confirmed by EDX microanalysis results [20,22]; (b) the measured nearly square hysteresis loop of Faraday rotation with high coercivity in $\mathrm{Bi}_{2} \mathrm{Dy}_{1} \mathrm{Fe}_{4.3} \mathrm{Ga}_{0.7} \mathrm{O}_{12}: \mathrm{Bi}_{2} \mathrm{O}_{3}$ composite film (having an estimated 24 vol.\% of excess $\mathrm{Bi}_{2} \mathrm{O}_{3}$ ) grown on a Corning 1737 glass substrate, showing different dynamics of the magnetization switching process in comparison with other films from the same batch sputtered onto GGG (111) substrates, revealed significant microstructural differences in layers grown onto different substrates type; and (c) shows the data on the time and temperature-dependent evolution of the measured $\mathrm{MO}$ figure of merits obtained in $\mathrm{Bi}_{2} \mathrm{Dy}_{1} \mathrm{Fe}_{4.3} \mathrm{Ga}_{0.7} \mathrm{O}_{12}: \mathrm{Bi}_{2} \mathrm{O}_{3}$ (17 \pm 2 vol.\%) films prepared on glass substrates. The data point distributions within data clusters shown within the circles followed the expected trends of MO quality factors for this material type at each of the optimized annealing temperatures.

\section{Conclusion}

We have prepared and characterized a large number of garnet-oxide composite-type thin films grown on both GGG and glass substrates during a study conducted in the area of magnetooptic functional materials reported previously in a string of our publications. The properties dataset of garnetoxide composite materials presented as well as the data related to the evolution of the optical and magnetooptical properties of particular batches of composite films occurring during annealing processes can be used as a guide for designing a range of optimized garnet-type thin film materials. 
This paper will be a useful reference for researchers working to produce functional magnetooptic garnet materials with application-specific material composition and properties suitable for a range of applications in integrated optics and photonics.

\section{Conflict of Interests}

The authors declare no conflict of interests.

\section{Acknowledgment}

The authors would like to acknowledge the extensive support for this work provided by the Electron Science Research Institute (ESRI), the Faculty of Health, Engineering and Science (FHES), Edith Cowan University (ECU), WA, Australia.

\section{References}

[1] A. K. Zvezdin and V. A. Kotov, Modern Magnetooptics and Magnetooptical Materials, Institute of Physics Publishing, Bristol, UK, 1997.

[2] M. Vasiliev, M. Nur-E-Alam, V. A. Kotov et al., "RF magnetron sputtered (BiDy)3(FeGa)5O12:Bi2O3 composite garnet-oxide materials possessing record magneto-optic quality in the visible spectral region," Optics Express, vol. 17, no. 22, pp. 19519-19535, 2009.

[3] S. Kahl, A. M. Grishin, S. I. Kharstev, K. Kawano, and J. S. Abell, " $\mathrm{Bi}_{3} \mathrm{Fe}_{5} \mathrm{O}_{12}$ thin film visulaizer," IEEE Transactions on Magnetics, vol. 3, no. 1, pp. 292-311, 2001.

[4] Y. Sun, H. Yu, H. Liu, Y. Zhou, and Z. Xia, "Study on Prsubstituted bismuth-iron garnet crystallite and its magnetism," Advanced Materials Research, vol. 415-417, pp. 495-498, 2012.

[5] V. I. Belotelov, L. E. Kreilkamp, I. A. Akimov et al., "Plasmonmediated magneto-optical transparency," Nature Communications, vol. 4, article 2128, 2013.

[6] V. Berzhansky, A. N. Shaposhnikov, A. V. Karavainikov et al., "The effect of Faraday rotation enhancement in nanolayered structures of $\mathrm{Bi}-$ substituted iron garnets," Solid State Phenomena, vol. 200, pp. 233-238, 2013.

[7] W. R. Eppler, B. K. Cheong, D. E. Laughlin, and M. H. Kryder, "Physical and magnetic microstructure of rapid thermally annealed thin film bismuth-doped garnets," Journal of Applied Physics, vol. 75, no. 10, pp. 7093-7095, 1994.

[8] A. Abdelrahman, M. Vasiliev, K. Alameh, and P. Hannaford, "Asymmetrical two-dimensional magnetic lattices for ultracold atoms," Physical Review A, vol. 82, no. 1, Article ID 012320, 2010.

[9] C. F. Buhrer, "Faraday rotation and dichroism of bismuth calcium vanadium iron garnet," Journal of Applied Physics, vol. 40, no. 11, pp. 4500-4502, 1969.

[10] G. B. Scott and D. E. Lacklison, "Magnetooptic properties and applications of bismuth substituted iron garnets," IEEE Transactions on Magnetics, vol. 12, no. 4, pp. 292-311, 1976.

[11] P. Hansen and J.-P. Krumme, "Magnetic and magneto-optical properties of garnet films," Thin Solid Films, vol. 114, no. 1-2, pp. 69-107, 1984.

[12] J.-P. Krumme, V. Doormann, and P. Willich, "Bismuth iron garnet films prepared by rf magnetron sputtering," Journal of Applied Physics, vol. 57, no. 8, pp. 3885-3887, 1985.
[13] M. Gomi, T. Tanida, and M. Abe, "RF sputtering of highly Bisubstituted garnet films on glass substrates for magneto-optic memory," Journal of Applied Physics, vol. 57, no. 8, pp. 38883890, 1985.

[14] T. Okuda, N. Koshizuka, K. Hayashi, T. Takahashi, H. Kotani, and H. Yamamoto, "Epitaxial growth of Bi-substituted yttrium iron garnet films by ion beam sputtering," Journal of the Magnetics Society of Japan, vol. 11, pp. 179-182, 1987.

[15] N. Adachi, V. P. Denysenkov, S. I. Khartsev, A. M. Grishin, and T. Okuda, "Epitaxial $\mathrm{Bi}_{3} \mathrm{Fe}_{5} \mathrm{O}_{12}$ (001) films grown by pulsed laser deposition and reactive ion beam sputtering techniques," Journal of Applied Physics, vol. 88, no. 1, pp. 2734-2739, 2000.

[16] T. Okuda, T. Katayama, H. Kobayashi, N. Kobayashi, K. Satoh, and $\mathrm{H}$. Yamamoto, "Magnetic properties of $\mathrm{Bi}_{3} \mathrm{Fe}_{5} \mathrm{O}_{12}$ garnet," Journal of Applied Physics, vol. 67, no. 9, pp. 4944-4946, 1990.

[17] S. Kahl and A. M. Grishin, "Evolution of properties of epitaxial bismuth iron garnet films with increasing thickness," Journal of Magnetism and Magnetic Materials, vol. 278, no. 1-2, pp. 244255, 2004.

[18] M. Huang and S. Zhang, "A new Bi-substituted rare-earth iron garnet for a wideband and temperature-stabilized optical isolator," Journal of Materials Research, vol. 15, no. 8, pp. 1665$1668,2000$.

[19] T. Tepper and C. A. Ross, "Pulsed laser deposition and refractive index measurement of fully substituted bismuth iron garnet films," Journal of Crystal Growth, vol. 255, no. 3-4, pp. 324-331, 2003.

[20] A. Mohammad, High performance magneto-optic garnet materials for integrated optics and photonics [Theses: Doctorates and Masters], 2012, Paper 528, http://ro.ecu.edu.au/theses/528.

[21] P. C. Wo, P. R. Munroe, M. Vasiliev, Z. H. Xie, K. Alameh, and V. Kotov, "A novel technique for microstructure characterization of garnet films," Optical Materials, vol. 32, no. 2, pp. 315-322, 2009.

[22] M. Vasiliev, M. Nur-E-Alam, K. Alameh et al., "Annealing behaviour and crystal structure of RF-sputtered Bi-substituted dysprosium iron-garnet films having excess co-sputtered $\mathrm{Bi}$ oxide content," Journal of Physics D: Applied Physics, vol. 44, no. 7, Article ID 075002, 2011.

[23] Joint Committee on Powder Diffraction Standards (JCPDS), Powder Diffraction Database and PCPDFWIN 1.30 Software, 1997.

[24] Z. Abbas, R. M. Al-Habashi, K. Khalid, and M. Maarof, "Garnet ferrite $\left(\mathrm{Y}_{3} \mathrm{Fe}_{5} \mathrm{O}_{12}\right)$ nanoparticles prepared via modified conventional mixing oxides (MCMO) method," European Journal of Scientific Research, vol. 36, no. 2, pp. 154-160, 2009. 

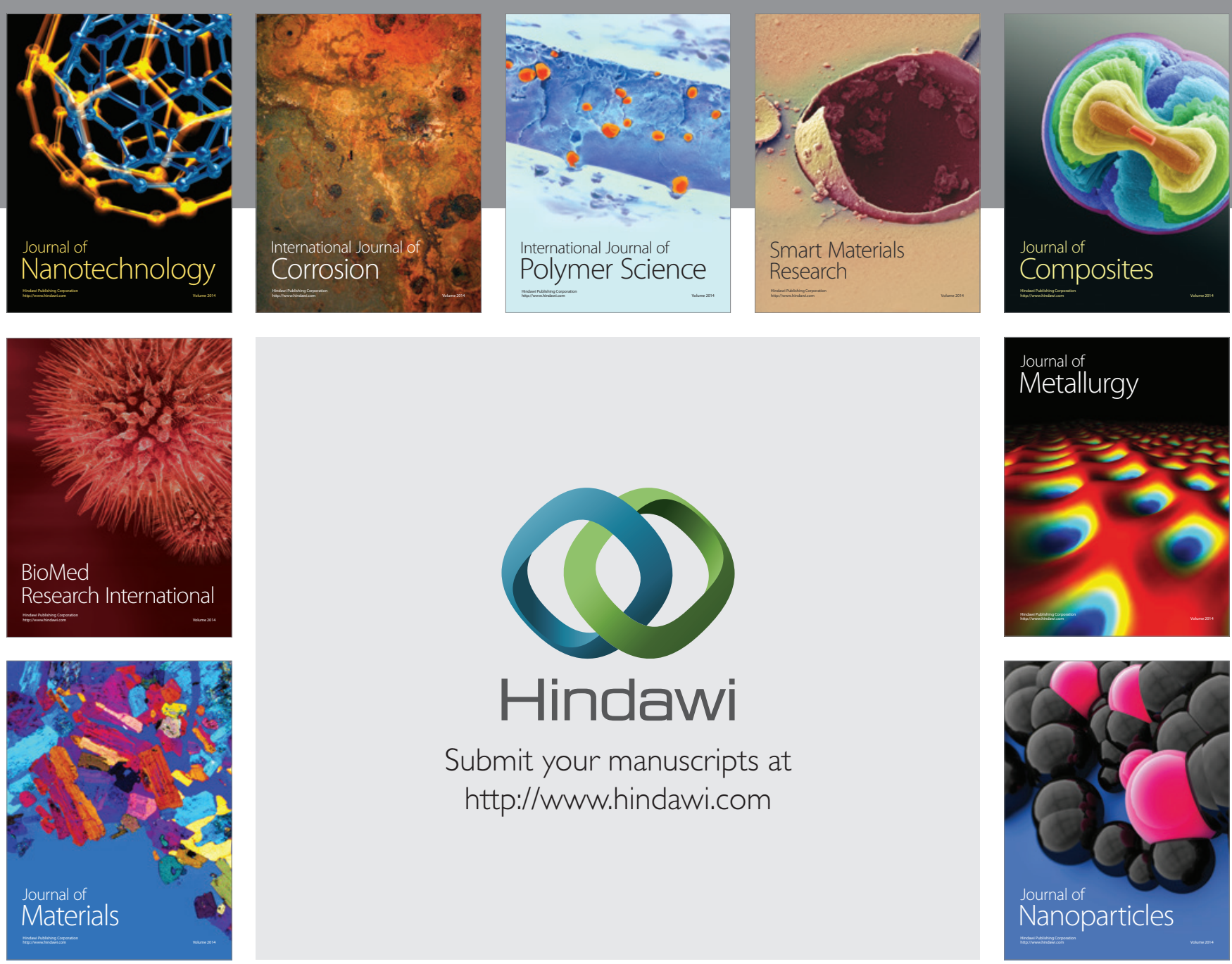

Submit your manuscripts at http://www.hindawi.com
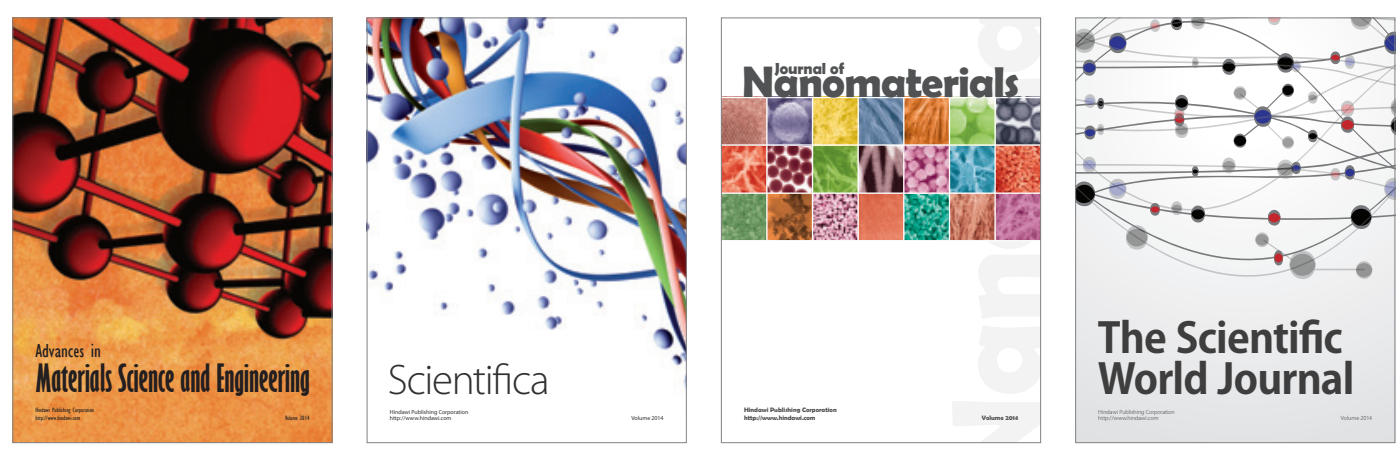

\section{The Scientific World Journal}
